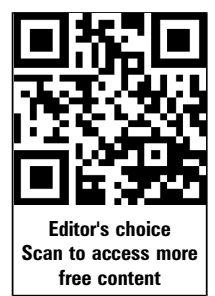

- Additional material is published online only. To view please visit the journal online (http://dx.doi.org/10.1136/ tobaccocontrol-2013-051159)

For numbered affiliations see end of article.

\section{Correspondence to} Dr Gary A Giovino, Department of Community Health and Health Behavior, School of Public Health and Health Professions, University at Buffalo, The State University of New York, 311 Kimball Tower, 3435 Main Street, Buffalo New York 14214-8028, USA; ggiovino@buffalo.edu

Received 24 May 2013 Accepted 8 August 2013 Published Online First 30 August 2013

\section{CrossMark}

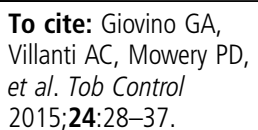

\title{
Differential trends in cigarette smoking in the USA: is menthol slowing progress?
}

\author{
Gary A Giovino, ${ }^{1}$ Andrea C Villanti, ${ }^{2,3}$ Paul D Mowery, ${ }^{4}$ Varadan Sevilimedu, ${ }^{4}$ \\ Raymond S Niaura, ${ }^{2,3}$ Donna M Vallone, ${ }^{3,5}$ David B Abrams ${ }^{2,3,6}$
}

\section{ABSTRACT}

Introduction Mentholated cigarettes are at least as dangerous to an individual's health as non-mentholated varieties. The addition of menthol to cigarettes reduces perceived harshness of smoke, which can facilitate initiation. Here, we examine correlates of menthol use, national trends in smoking menthol and non-menthol cigarettes, and brand preferences over time.

Methods We estimated menthol cigarette use during 2004-2010 using annual data on persons $\geq 12$ years old from the National Surveys on Drug Use and Health. We adjusted self-reported menthol status for selected brands that were either exclusively menthol or nonmenthol, based on sales data. Data were weighted to provide national estimates.

Results Among cigarette smokers, menthol cigarette use was more common among $12-17$ year olds $(56.7 \%)$ and $18-25$ year olds $(45.0 \%)$ than among older persons (range $30.5 \%$ to $34.7 \%$ ). In a multivariable analysis, menthol use was associated with being younger, female and of non-Caucasian race/ethnicity. Among all adolescents, the percentage who smoked non-menthol cigarettes decreased from 2004-2010, while menthol smoking rates remained constant; among all young adults, the percentage who smoked non-menthol cigarettes also declined, while menthol smoking rates increased. The use of Camel menthol and Marlboro menthol increased among adolescent and young adult smokers, particularly non-Hispanic Caucasians, during the study period.

Conclusions Young people are heavy consumers of mentholated cigarettes. Progress in reducing youth smoking has likely been attenuated by the sale and marketing of mentholated cigarettes, including emerging varieties of established youth brands. This study should inform the Food and Drug Administration regarding the potential public health impact of a menthol ban.

\section{INTRODUCTION}

Smokers of mentholated cigarettes are just as likely to experience premature morbidity and mortality as smokers of non-mentholated varieties, ${ }^{1}$ even though menthol smokers smoke fewer cigarettes per day than do smokers of non-mentholated brands. $^{2}{ }^{3}$ The cooling properties and flavour of menthol make these cigarettes less harsh to smoke, ${ }^{4}$ which can facilitate the transition from experimentation to more regular use and addiction. ${ }^{56}$

Consistent with evidence that young smokers prefer flavoured cigarettes, ${ }^{7}$ studies of adolescent and adult smokers find the highest prevalences of menthol cigarette use among 12-17-year-old smokers compared to older smokers and among middle school smokers when compared with high school smokers. ${ }^{5-10}$ A recent National Survey on Drug Use and Health (NSDUH) report on menthol smoking showed that trends in past month menthol use increased from $13.4 \%$ in 2004 to $15.9 \%$ in 2010 among people aged 18-25 years old, and remained relatively stable from 2004-2010 among those aged $12-17$ years and 26 years and older. ${ }^{11}$ Menthol cigarette use appears to be more common among more recent initiates, suggesting a role as a starter product for youth. ${ }^{4511}$ Menthol may facilitate nicotine addiction. Several studies report increased nicotine dependence among adolescent menthol smokers compared to non-menthol smokers. ${ }^{5}$ 12-14 Menthol has also been shown to increase oral absorption of nicotine in an animal model. ${ }^{15}$

The 2009 Family Smoking Prevention and Tobacco Control Act ${ }^{16}$ gives the Food and Drug Administration (FDA) authority to issue tobacco product standards if deemed 'appropriate for the protection of public health'. ${ }^{16}$ The Act required the FDA to ban fruit, candy, or clove characterising flavourings in cigarettes in September 2009 to reduce youth smoking initiation. ${ }^{17}$ The Act did not ban menthol flavourings at that time. Rather, it directed the FDA's Tobacco Products Scientific Advisory Committee (TPSAC) to review the scientific evidence on the impact of the use of menthol in cigarettes on the public health, including such use among children, African-Americans, Hispanics and other racial and ethnic minorities. TPSAC concluded in its July 2011 report that 'removal of menthol cigarettes from the marketplace would benefit public health in the USA' ${ }^{18}$ TPSAC's conclusions were based in part on analyses of 20042008 NSDUH data. ${ }^{19}$ In this study, we update and extend these analyses with 2009 and 2010 NSDUH data to examine correlates of menthol use, trends in the prevalence of smoking menthol and nonmenthol cigarettes in the USA, and changes in preference for various mentholated brands across subgroups and with increased precision.

\section{METHODS}

\section{National Survey on Drug Use and Health}

The NSDUH is a nationally representative survey that assesses tobacco, alcohol and drug use behaviours in the US civilian, non-institutionalised population that is $\geq 12$ years old. It is administered to a sample of the US population living in households. Respondents include residents of non-institutional group quarters, such as college students living in dormitories, civilians residing on military bases, and persons living in group homes, shelters and rooming houses. The NSDUH is sponsored by the Substance 
Abuse and Mental Health Services Administration. Cross-sectional surveys administered annually from 2004 to 2010 were used to estimate the prevalence of menthol use among current smokers and among the entire population. NSDUH respondents are selected using a multistage probability sample. Most interviews are conducted in the respondents' homes by trained interviewers. To decrease misclassification bias, drug use questions-including tobacco questions - are administered by audio computer-assisted self-interviews (A-CASI). The overall response rate for the 2004-2010 individual survey years ranged from $66.1 \%$ to $70.0 \%$. The NSDUH added a new question on menthol use in $2004 .^{20}$

Current cigarette smoking in the NSDUH was assessed by asking respondents who had ever smoked whether they had smoked part or all of a cigarette in the previous 30 days. Those who responded affirmatively were subsequently asked to report the brand of cigarettes they smoked most often. They were able to select and verify their usual brand from 2 lists with a total of 57 (60 in 2004) brand names that were presented onscreen. Once respondents selected and verified one of the brands on the screen, they were subsequently asked, 'Were the <CIGFILL> cigarettes you smoked during the past 30 days menthol?' (Note: '<CIGFILL $>$ ' was replaced by the computer programme with the name of the brand the respondent had previously reported and verified as having smoked most often.) Approximately 95\% of smokers selected a brand from the lists offered. The remaining 5\% were asked, 'Were the cigarettes you smoked during the past 30 days menthol?'

Prior research has demonstrated under-reporting of menthol status of exclusively menthol brands (eg, Newport, Salem), particularly among adolescent smokers. ${ }^{2} 521$ This has been raised as a particular concern for estimates of menthol use among young Black smokers. ${ }^{21}$ Because of concerns about misclassification, especially among adolescents (see online supplementary tables S1 and S2), we used sales data ${ }^{22}$ to classify major brands for which at least $99 \%$ of sales were menthol or non-menthol. Sales data were incorporated for 2008 grocery, drug and merchandise stores and for 2009 and 2010 for those types of stores and convenience stores, as well (see supplementary Appendix). Incorporating a method of Hersey and colleagues, ${ }^{5}$ if a respondent reported usually smoking Newport and also reported on the menthol question that the usual brand was non-menthol, the respondent's response to the menthol variable question was recoded as menthol. A similar adjustment was made for exclusively non-mentholated brands. All results reported here use this adjustment process. We note that the overall prevalence trends observed here were also observed with unadjusted data. ${ }^{11}$

\section{Statistical analyses}

We used SAS V.9.2 for all analyses. The SAS survey procedures took into account NSDUH's complex survey design. Survey weights were used to adjust for different probabilities of selection and for non-response, producing estimates representative of the US population. Due to small cell sizes, we restricted some of our analyses to the three largest racial/ethnic groups: non-Hispanic Caucasian, non-Hispanic Black and Hispanic.

We used data on 40841 smokers interviewed in 2008-2010 who were aged 12 years and older to assess patterns of menthol use among smokers by age, gender, race/ethnicity, household income and the number of days smoked during the previous 30 days. Differences in point estimates were assessed using nonoverlapping CIs. Logistic regression analyses were conducted to assess patterns of use in a multivariable model.
We then used data on 389698 respondents aged 12 years and older to estimate the prevalence of smoking menthol and nonmenthol cigarettes in the US population. These estimates were made by age (12-17, 18-25, 26 years and older) and in each age group by gender and race/ethnicity. The significance of the time trends was tested using a $t$ test of the slope coefficients. This was performed separately for menthol and non-menthol trend lines. The difference between menthol and non-menthol time trends was estimated by including an interaction term in the model. The interaction term enabled us to estimate separate slopes for menthol and non-menthol trend lines. We tested the significance of the interaction coefficient using a t test of the interaction coefficient.

We also compared data on 43616 smokers surveyed during 2004-2006 with those from the 40841 smokers surveyed during 2008-2010 to assess changes in menthol brand preference. Our intention in this analysis was to contrast the 3 earliest years of the study with the 3 latest years. Including data from 2007 would have resulted in an unbalanced analysis. Differences in use of various brands over time were tested using the $\mathrm{z}$ test of two independent binomial proportions.

\section{A note on terminology}

Below we refer to persons aged 12-17 years old as adolescents, 18-25 years old as young adults and 26 years and older as adults. We refer to non-Hispanic Caucasian subjects as Caucasians, non-Hispanic Black subjects as Blacks and non-Hispanic Asian subjects as Asians.

Additional details on the methods used and results are presented in the online supplementary appendix.

\section{RESULTS \\ Age differences in menthol cigarette use among current cigarette smokers}

Table 1 presents overall and age-specific data on the use of mentholated cigarettes among current smokers during 2008-2010 by gender, race/ethnicity, household income and the number of days smoked during the previous 30 days. Menthol use was most prevalent among adolescent smokers overall $(56.7 \%$, representing 1.2 million smokers) and consistently high across all subgroups examined. Prevalence of menthol use was next highest among young adult smokers overall (45.0\%, representing 5.2 million smokers) and in most subcategories. Overall, lower menthol use rates were observed among 26-34 year olds (34.7\%), which were higher than among 35-49 (30.5\%) and 50+ (30.7\%) year olds. Among Blacks, a ceiling effect likely occurred, with menthol use rates of at least $89.9 \%$ observed in each of the 12-49-year-old age categories.

\section{Multivariable analyses}

More precise younger age categories were examined in a multivariable logistic regression analysis of correlates of menthol cigarette use among smokers (table 2). Controlling for gender, race/ethnicity, household income and days smoked in the past month, the odds of smoking mentholated brands were highest in the youngest age groups (12-15 and 16-17) of smokers. Females and racial/ethnic minority groups were more likely to smoke mentholated varieties than were males and Caucasians, respectively. Of particular note, Blacks had 25.18 times higher odds (95\% CI 20.28 to 31.26 ) of smoking menthol cigarettes compared to Caucasians. No differences were seen across categories of household income and days smoked/month. 
Table 1 Prevalence (\%) of use of menthol cigarettes among past 30-day smokers, by age and gender, race/ethnicity, household income and the number of days smoked/month in the USA,

2008-2010

\begin{tabular}{|c|c|c|c|c|c|c|c|c|c|c|c|c|}
\hline \multirow[b]{2}{*}{ Factor } & \multicolumn{2}{|c|}{ All ages } & \multicolumn{2}{|l|}{$12-17$} & \multicolumn{2}{|l|}{$18-25$} & \multicolumn{2}{|l|}{$26-34$} & \multicolumn{2}{|l|}{$35-49$} & \multicolumn{2}{|l|}{$50+$} \\
\hline & $\%$ & $95 \% \mathrm{Cl}$ & $\%$ & $95 \% \mathrm{Cl}$ & $\%$ & $95 \% \mathrm{Cl}$ & $\%$ & $95 \% \mathrm{Cl}$ & $\%$ & $95 \% \mathrm{Cl}$ & $\%$ & $95 \% \mathrm{Cl}$ \\
\hline Overall & 35.23 & 34.19 to 36.27 & 56.71 & 54.62 to 58.80 & 45.01 & 43.80 to 46.22 & 34.74 & 32.87 to 36.62 & 30.50 & 29.13 to 31.87 & 30.74 & 28.27 to 33.22 \\
\hline \multicolumn{13}{|l|}{ Gender } \\
\hline Male & 31.40 & 30.24 to 32.55 & 53.79 & 51.34 to 56.24 & 41.94 & 40.45 to 43.42 & 32.67 & 30.16 to 35.18 & 25.15 & 23.48 to 26.82 & 25.70 & 22.53 to 28.87 \\
\hline Female & 39.65 & 38.11 to 41.19 & 59.87 & 57.15 to 62.58 & 48.95 & 47.36 to 50.53 & 37.42 & 34.90 to 39.94 & 36.46 & 34.40 to 38.52 & 35.87 & 32.51 to 39.23 \\
\hline \multicolumn{13}{|l|}{ Race/ethnicity } \\
\hline Non-Hispanic Caucasian & 25.70 & 24.71 to 26.69 & 51.30 & 48.84 to 53.77 & 36.39 & 35.12 to 37.66 & 23.58 & 21.96 to 25.20 & 20.05 & 18.58 to 21.53 & 22.63 & 20.53 to 24.73 \\
\hline Non-Hispanic Black & 88.47 & 86.24 to 90.71 & 94.89 & 92.68 to 97.11 & 93.97 & 92.57 to 95.37 & 91.61 & 88.48 to 94.74 & 89.93 & 86.43 to 93.44 & 80.99 & 75.39 to 86.58 \\
\hline Non-Hispanic other & 45.19 & 37.25 to 53.12 & 56.49 & 44.50 to 68.49 & 56.28 & 49.24 to 63.31 & 38.68 & 25.65 to 51.71 & 48.47 & 31.43 to 65.51 & 31.58 & 13.12 to 50.04 \\
\hline Non-Hispanic Asian & 30.77 & 26.41 to 35.13 & 60.71 & 41.48 to 79.94 & 49.77 & 42.57 to 56.97 & 27.05 & 17.17 to 36.92 & 24.91 & 14.72 to 35.10 & 16.96 & 3.62 to 30.29 \\
\hline Non-Hispanic more than one race & 42.16 & 34.57 to 49.75 & 59.39 & 49.71 to 69.07 & 52.81 & 46.09 to 59.53 & 30.86 & 23.03 to 38.69 & 48.16 & 37.89 to 58.43 & 33.75 & 14.87 to 52.63 \\
\hline Hispanic & 38.06 & 35.70 to 40.43 & 58.18 & 52.20 to 64.15 & 47.33 & 44.50 to 50.16 & 40.45 & 35.38 to 45.52 & 31.86 & 26.40 to 37.32 & 26.82 & 18.23 to 35.40 \\
\hline \multicolumn{13}{|l|}{ Household income } \\
\hline Lower tertile & 40.68 & 38.85 to 42.51 & 58.32 & 54.59 to 62.05 & 45.99 & 43.93 to 48.06 & 44.95 & 41.20 to 48.69 & 38.92 & 35.99 to 41.85 & 32.97 & 29.09 to 36.84 \\
\hline Middle tertile & 35.81 & 34.17 to 37.46 & 58.02 & 54.23 to 61.81 & 45.05 & 43.28 to 46.83 & 35.55 & 32.45 to 38.66 & 30.37 & 28.14 to 32.60 & 32.44 & 28.47 to 36.41 \\
\hline Higher tertile & 31.20 & 29.75 to 32.65 & 55.01 & 51.75 to 58.27 & 43.99 & 42.42 to 45.56 & 28.04 & 25.65 to 30.43 & 26.42 & 24.13 to 28.72 & 27.57 & 24.03 to 31.10 \\
\hline \multicolumn{13}{|l|}{ Number of days smoked per month } \\
\hline $1-5$ days & 39.50 & 37.35 to 41.65 & 57.78 & 54.03 to 61.53 & 43.76 & 41.67 to 45.84 & 32.90 & 28.28 to 37.52 & 34.21 & 29.53 to 38.89 & 39.26 & 32.30 to 46.22 \\
\hline $6-29$ days & 41.30 & 39.44 to 43.15 & 58.70 & 55.30 to 62.09 & 46.82 & 44.57 to 49.06 & 37.77 & 34.03 to 41.51 & 37.06 & 34.00 to 40.12 & 38.87 & 32.66 to 45.08 \\
\hline 30 days & 31.92 & 30.71 to 33.13 & 51.98 & 48.55 to 55.40 & 44.53 & 43.12 to 45.93 & 34.09 & 31.73 to 36.45 & 27.73 & 26.13 to 29.33 & 27.88 & 25.16 to 30.59 \\
\hline
\end{tabular}


Table 2 Multivariate logistic regression analysis of correlates of use of menthol cigarettes among past 30-day smokers in the USA, 2008-2010

\begin{tabular}{|c|c|c|c|c|c|}
\hline Factor & $\mathbf{N}$ & Menthol, \% & AOR & $95 \% \mathrm{Cl}$ & $\mathrm{p}$ Value \\
\hline \multicolumn{6}{|l|}{ Age (years) } \\
\hline $12-15$ & 1644 & 58.42 & 3.92 & 3.32 to 4.63 & $<0.0001$ \\
\hline $16-17$ & 3251 & 55.82 & 3.62 & 3.25 to 4.03 & $<0.0001$ \\
\hline $18-21$ & 10095 & 48.37 & 2.61 & 2.34 to 2.90 & $<0.0001$ \\
\hline $22-25$ & 10172 & 41.58 & 1.85 & 1.69 to 2.03 & $<0.0001$ \\
\hline $26-34$ & 5889 & 34.75 & 1.26 & 1.16 to 1.37 & $<0.0001$ \\
\hline $35+$ & 9755 & 30.61 & Reference & & \\
\hline \multicolumn{6}{|l|}{ Gender } \\
\hline Female & 19780 & 39.62 & 1.62 & 1.49 to 1.76 & $<0.0001$ \\
\hline Male & 21026 & 31.40 & Reference & & \\
\hline \multicolumn{6}{|l|}{ Race/ethnicity } \\
\hline Non-Hispanic Black & 4337 & 88.46 & 25.18 & 20.28 to 31.26 & $<0.0001$ \\
\hline Non-Hispanic Asian & 787 & 30.76 & 1.35 & 1.10 to 1.66 & 0.004 \\
\hline Non-Hispanic more than one race & 1546 & 42.00 & 2.06 & 1.51 to 2.80 & $<0.0001$ \\
\hline Non-Hispanic other & 1227 & 45.19 & 2.26 & 1.64 to 3.12 & $<0.0001$ \\
\hline Hispanic & 5137 & 38.09 & 1.81 & 1.62 to 2.02 & $<0.0001$ \\
\hline Non-Hispanic Caucasian & 27772 & 25.70 & Reference & & \\
\hline \multicolumn{6}{|l|}{ Household income } \\
\hline Lower tertile & 11971 & 40.64 & 0.95 & 0.84 to 1.08 & 0.44 \\
\hline Middle tertile & 15253 & 35.81 & 1.02 & 0.92 to 1.12 & 0.77 \\
\hline Higher tertile & 13582 & 31.21 & Reference & & \\
\hline \multicolumn{6}{|l|}{ Number of days smoked/month } \\
\hline $1-5$ days & 8487 & 39.50 & 1.01 & 0.91 to 1.13 & 0.82 \\
\hline $6-29$ days & 10427 & 41.30 & 1.02 & 0.92 to 1.12 & 0.73 \\
\hline 30 days & 21892 & 31.92 & Reference & & \\
\hline
\end{tabular}

Source: National Survey on Drug Use and Health 2008-2010. Self-reported menthol status was adjusted if necessary using retail checkout scanner data. Sample size=40 806 .

\section{Recent trends in the prevalence of smoking menthol and non-menthol cigarettes in the USA}

Figure 1 and table 3 and online supplementary table S3 show the results of analyses that examined overall trends from 20042010 in the prevalence of smoking menthol and non-menthol cigarettes among adolescents, young adults and adults. Note that the denominator here is all individuals in the relevant age groups, not just cigarette smokers. Overall, 5.3\% of adolescents smoked mentholated cigarettes in 2004, compared to $4.5 \%$ in 2010; 6.0\% smoked non-mentholated cigarettes in 2004, compared to $3.4 \%$ in 2010 . The slopes of the regression lines were $-0.08(\mathrm{p}=0.11)$ for menthol smoking and $-0.47(\mathrm{p}<0.001)$ for non-menthol smoking. The slopes of these two lines were significantly different $(\mathrm{p}<0.001)$.

Among young adults, $14.0 \%$ smoked mentholated cigarettes in 2004 , compared to $16.3 \%$ in $2010 ; 25.7 \%$ smoked nonmentholated cigarettes in 2004, compared to $17.3 \%$ in 2010. The slopes of the regression lines were $+0.45(p=0.003)$ for menthol smoking and $-1.48 \quad(\mathrm{p}<0.001)$ for non-menthol. These slopes were also significantly different $(p<0.001)$. Among adults aged 26 and above, $7.0 \%$ smoked mentholated cigarettes in 2004 , compared to $7.4 \%$ in $2010 ; 17.0 \%$ smoked non-mentholated cigarettes in 2004, compared to $15.3 \%$ in 2010. The slopes of the regression lines were $+0.04 \quad(p=0.46)$ for menthol smoking and $-0.28(\mathrm{p}=0.0024)$ for non-menthol. These slopes were significantly different $(p=0.0013)$.

The general pattern of more rapid decline of non-menthol smoking relative to menthol smoking was consistently observed among males, females and Caucasians ( $\mathrm{p}=0.053$ for adults) and among young adult and adult Hispanics (table 3 ).

\section{Trends in prevalence of various mentholated cigarette brands by US cigarette smokers}

Next, we compared preference for leading mentholated varieties in 2004-2006 and 2008-2010 among smokers across age categories (see online supplementary figure S1 and table S4). Preference for Camel menthol and Marlboro menthol cigarettes increased during the study in all three age groups, but especially among adolescents and young adults. Newport use increased among young adults and adults; Salem use declined in all three age groups. Overall, the number of users of Camel menthol, Marlboro menthol and Newport increased during the study by approximately 866000,886000 and 580000 smokers, respectively (see online supplementary table S4). During 2008-2010, 1.0 million adolescents and 4.6 million young adults used Camel menthol, Marlboro menthol, or Newport.

The prevalence of Camel menthol use increased significantly among Caucasians in all age groups, among adolescent Blacks, and among Hispanic young adults and adults (figure 2 and see online supplementary table S5). The prevalence of smoking Marlboro menthol cigarettes increased among Caucasians in all age groups and among Black and Hispanic young adults. Prevalence of use of Kool and Salem declined in some age categories, and Newport use increased among adult Blacks.

\section{DISCUSSION}

The analyses in this report indicate that youth are heavy consumers of mentholated cigarettes and that overall menthol cigarette smoking has either remained constant or increased from 2004-2010 in all three age groups, while non-menthol smoking has decreased. We also document increased use of Camel 
Adolescents ages 12-17

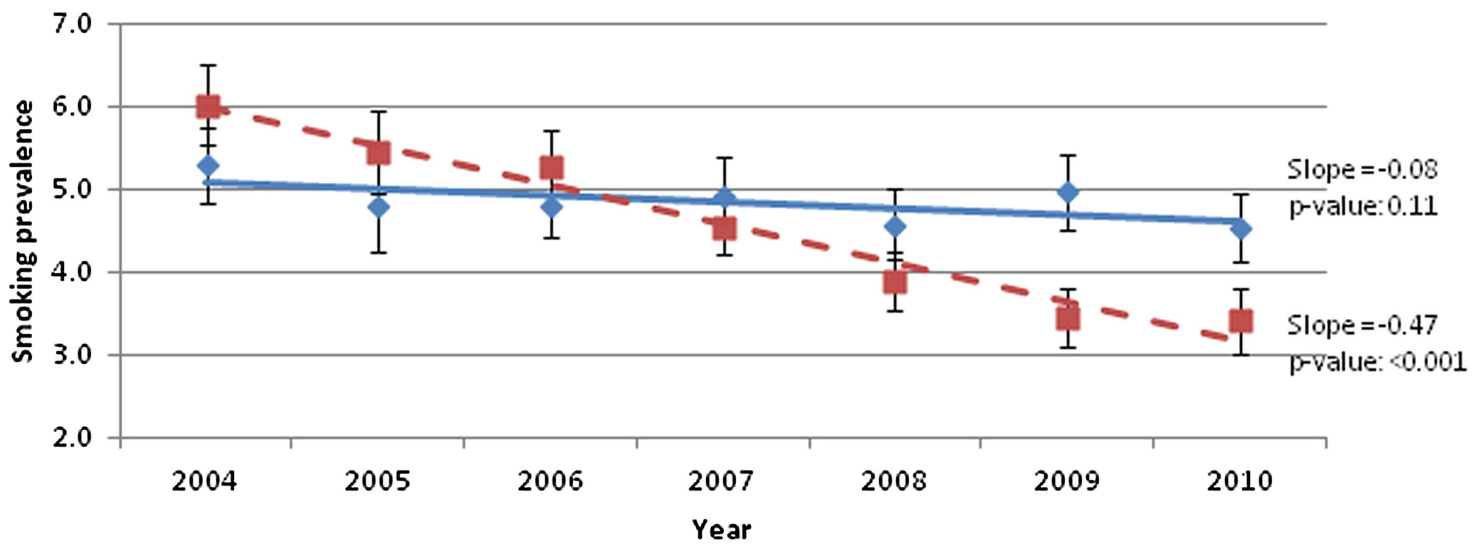

Young adults ages $\mathbf{1 8 - 2 5}$

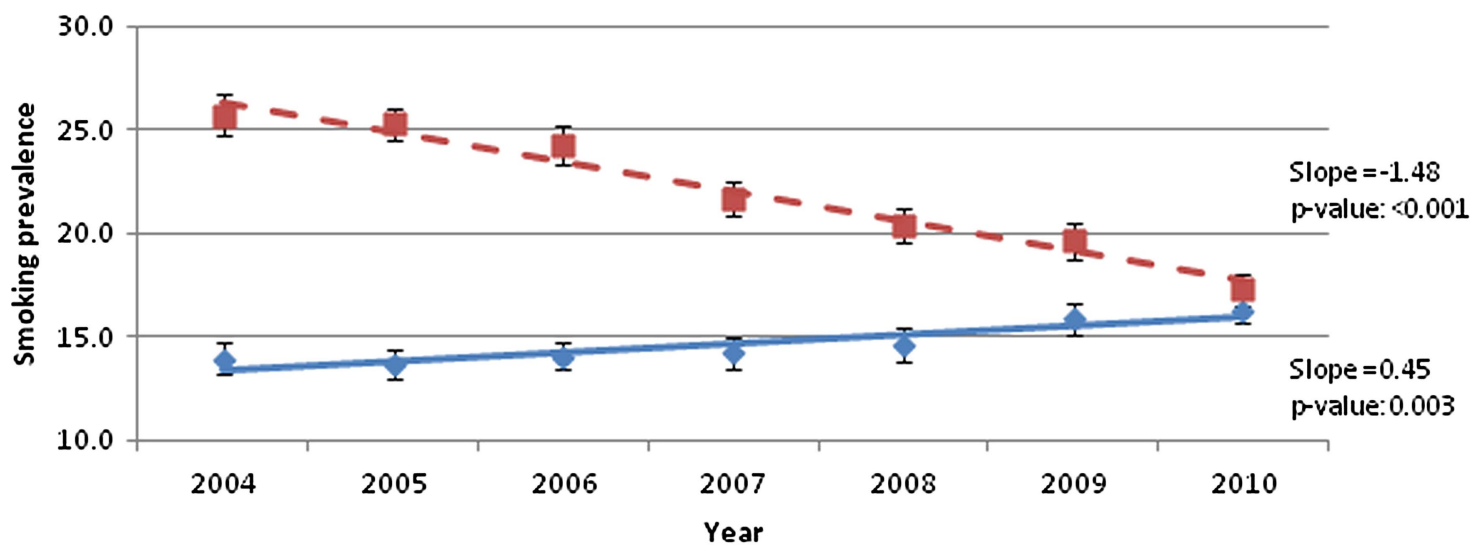

Adults ages 26+

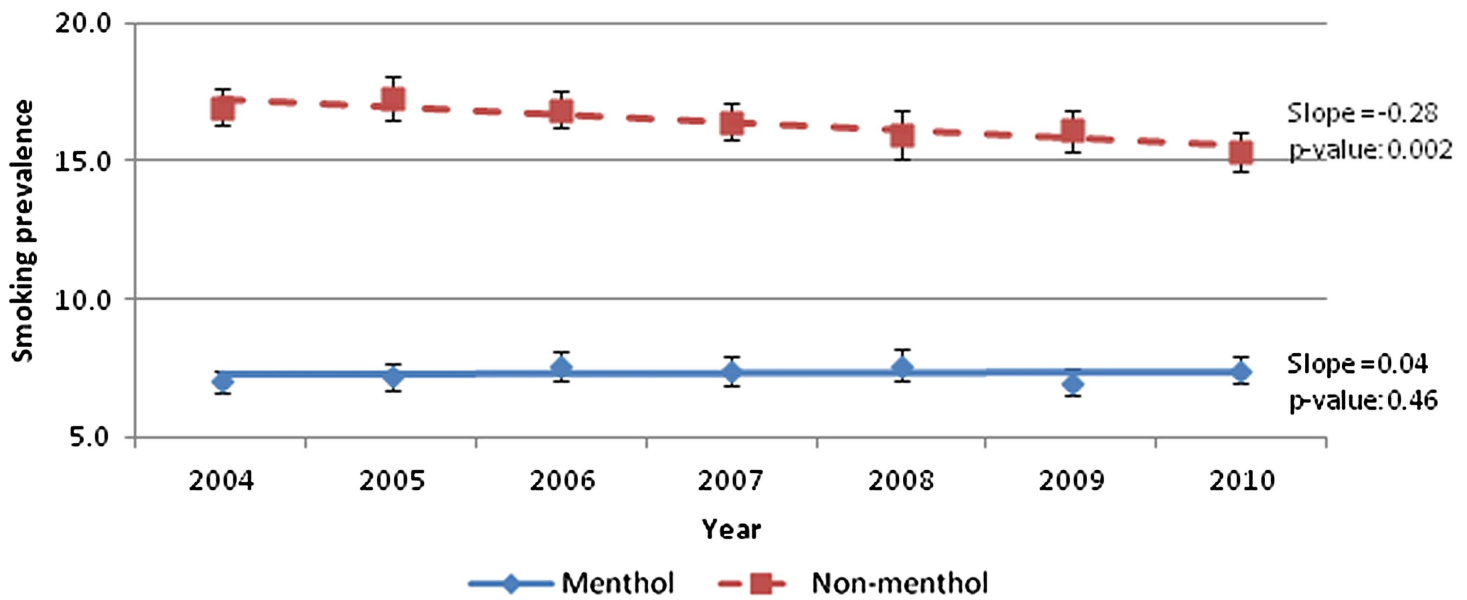

Figure 1 Trends in the prevalence of cigarette smoking (\%) by type of cigarette smoked and age in the USA, 2004-2010. Source: National Survey on Drug Use and Health. Self-reported menthol status was adjusted if necessary using retail checkout scanner data. NB: Scales for y-axis are different across age groups. Menthol cigarette use represented by solid blue line; non-menthol cigarette use by broken red line. Error bars represent $95 \%$ Cls. Differences in slopes for menthol and non-menthol cigarette use in adolescents $(p<0.001)$, young adults $(p<0.001)$ and adults $(p=0.0013)$. Sample size $=389698$.

menthol and Marlboro menthol cigarettes, particularly among young Caucasians and Hispanics. Camel menthol and Marlboro menthol are emerging varieties of established youth brands. ${ }^{23}$ Our findings address previous concerns regarding misclassification of menthol smoking status by adjusting self-reported menthol status with Nielsen retail checkout scanner data. ${ }^{22}$
After such adjustment, we observed that more than half $(56.7 \%)$ of adolescent smokers preferred menthol cigarettes. Detailed findings are discussed below.

First, after controlling for confounders, younger age, even as young as $12-15$ years old, was a significant correlate of menthol cigarette use. The relationship between age and menthol use 
Table 3 Trends in the prevalence of cigarette smoking (\%) by type of cigarette smoked and age, gender and race/ethnicity in the USA, 2004-2010

\begin{tabular}{|c|c|c|c|c|c|c|c|c|c|c|}
\hline \multirow{2}{*}{$\begin{array}{l}\text { Type of cigarette } \\
\text { smoked/factor }\end{array}$} & \multicolumn{7}{|c|}{ Percentage } & \multirow{2}{*}{$\begin{array}{l}\text { Estimated } \\
\text { slope }\end{array}$} & \multirow{2}{*}{$\begin{array}{l}p \text { Value } \\
\text { for slope }\end{array}$} & \multirow{2}{*}{$\begin{array}{l}\text { p Value fo } \\
\text { difference } \\
\text { in slopes }\end{array}$} \\
\hline & 2004 & 2005 & 2006 & 2007 & 2008 & 2009 & 2010 & & & \\
\hline \multicolumn{11}{|l|}{ 12-17 years: } \\
\hline \multicolumn{11}{|l|}{ Overall } \\
\hline Menthol & 5.3 & 4.8 & 4.8 & 4.9 & 4.6 & 5.0 & 4.5 & -0.08 & 0.11 & $<0.001$ \\
\hline Non-menthol & 6.0 & 5.5 & 5.3 & 4.5 & 3.9 & 3.5 & 3.4 & -0.47 & $<0.001$ & \\
\hline \multicolumn{11}{|l|}{ Gender: } \\
\hline \multicolumn{11}{|l|}{ Male } \\
\hline Menthol & 4.6 & 4.3 & 4.3 & 4.8 & 4.4 & 4.8 & 4.4 & 0.00 & 0.95 & $<0.001$ \\
\hline Non-menthol & 6.2 & 5.7 & 5.4 & 4.9 & 4.0 & 3.9 & 3.8 & -0.43 & $<0.001$ & \\
\hline \multicolumn{11}{|l|}{ Female } \\
\hline Menthol & 6.0 & 5.3 & 5.3 & 5.0 & 4.8 & 5.1 & 4.7 & -0.18 & 0.01 & $<0.001$ \\
\hline Non-menthol & 5.8 & 5.2 & 5.1 & 4.2 & 3.8 & 3.0 & 3.0 & -0.52 & $<0.001$ & \\
\hline \multicolumn{11}{|l|}{ Race/ethnicity: } \\
\hline \multicolumn{11}{|c|}{ Non-Hispanic Caucasian } \\
\hline Menthol & 5.8 & 4.8 & 4.9 & 5.5 & 4.8 & 5.2 & 5.1 & -0.02 & 0.79 & $<0.001$ \\
\hline Non-menthol & 8.1 & 7.5 & 7.2 & 6.3 & 5.2 & 5.0 & 4.2 & -0.69 & $<0.001$ & \\
\hline \multicolumn{11}{|l|}{ Non Hispanic Black } \\
\hline Menthol & 5.3 & 6.1 & 5.7 & 5.8 & 4.9 & 4.8 & 4.2 & -0.23 & 0.04 & 0.11 \\
\hline Non-menthol & 0.5 & 0.5 & 0.1 & 0.3 & 0.2 & 0.2 & 0.3 & 0.03 & 0.48 & \\
\hline \multicolumn{11}{|l|}{ Hispanic } \\
\hline Menthol & 3.7 & 4.3 & 4.2 & 3.1 & 3.8 & 4.6 & 3.8 & -0.01 & 0.90 & 0.30 \\
\hline Non-menthol & 4.4 & 3.4 & 3.5 & 2.8 & 3.1 & 2.2 & 3.4 & -0.18 & 0.16 & \\
\hline \multicolumn{11}{|l|}{ 18-25 years: } \\
\hline \multicolumn{11}{|l|}{ Overall } \\
\hline Menthol & 14.0 & 13.7 & 14.1 & 14.2 & 14.6 & 15.9 & 16.3 & 0.45 & 0.003 & $<0.001$ \\
\hline Non-menthol & 25.7 & 25.3 & 24.2 & 21.6 & 20.4 & 19.6 & 17.3 & -1.48 & $<0.001$ & \\
\hline Gender: & & & & & & & & & & \\
\hline Male & & & & & & & & & & \\
\hline Menthol & 14.4 & 14.0 & 14.4 & 14.9 & 15.4 & 16.3 & 17.0 & 0.50 & 0.001 & $<0.001$ \\
\hline Non-menthol & 29.5 & 28.9 & 27.3 & 25.2 & 23.7 & 23.6 & 20.2 & -1.57 & $<0.001$ & \\
\hline Female & & & & & & & & & & \\
\hline Menthol & 13.6 & 13.3 & 13.8 & 13.5 & 13.9 & 15.5 & 15.6 & 0.35 & 0.02 & $<0.001$ \\
\hline Non-menthol & 21.9 & 21.6 & 21.1 & 18.0 & 17.1 & 15.6 & 14.3 & -1.35 & $<0.001$ & \\
\hline Race/ethnicity: & & & & & & & & & & \\
\hline Non-Hispanic Cauca & & & & & & & & & & \\
\hline Menthol & 12.3 & 11.8 & 12.7 & 12.5 & 13.1 & 14.5 & 15.6 & 0.56 & 0.01 & $<0.001$ \\
\hline Non-menthol & 33.0 & 32.5 & 31.5 & 28.1 & 26.8 & 26.0 & 22.8 & -1.76 & $<0.001$ & \\
\hline Non Hispanic Black & & & & & & & & & & \\
\hline Menthol & 27.5 & 26.0 & 25.0 & 24.0 & 24.5 & 24.2 & 24.6 & -0.44 & 0.04 & 0.13 \\
\hline Non-menthol & 2.0 & 2.3 & 1.7 & 1.8 & 1.2 & 1.9 & 1.5 & -0.10 & 0.21 & \\
\hline Hispanic & & & & & & & & & & \\
\hline Menthol & 11.2 & 11.4 & 11.4 & 12.9 & 13.1 & 14.1 & 12.7 & 0.40 & 0.03 & $<0.001$ \\
\hline Non-menthol & 20.6 & 20.5 & 17.5 & 15.9 & 16.0 & 14.6 & 13.9 & -1.14 & $<0.001$ & \\
\hline 26+ years: & & & & & & & & & & \\
\hline Overall & & & & & & & & & & \\
\hline Menthol & 7.0 & 7.2 & 7.6 & 7.4 & 7.6 & 7.0 & 7.4 & 0.04 & 0.46 & 0.001 \\
\hline Non-menthol & 16.9 & 17.2 & 16.8 & 16.4 & 15.9 & 16.1 & 15.3 & -0.28 & 0.002 & \\
\hline Gender: & & & & & & & & & & \\
\hline Male & & & & & & & & & & \\
\hline Menthol & 6.8 & 6.7 & 7.5 & 7.4 & 7.4 & 6.5 & 7.1 & 0.03 & 0.76 & 0.003 \\
\hline Non-menthol & 20.3 & 20.7 & 19.9 & 19.4 & 18.8 & 18.5 & 18.2 & -0.40 & $<0.001$ & \\
\hline Female & & & & & & & & & & \\
\hline Menthol & 7.3 & 7.7 & 7.6 & 7.3 & 7.8 & 7.4 & 7.7 & 0.02 & 0.65 & 0.04 \\
\hline Non-menthol & 13.9 & 14.1 & 14.0 & 13.7 & 13.3 & 13.9 & 12.7 & -0.17 & 0.07 & \\
\hline
\end{tabular}


Table 3 Continued

\begin{tabular}{|c|c|c|c|c|c|c|c|c|c|c|}
\hline \multirow{2}{*}{$\begin{array}{l}\text { Type of cigarette } \\
\text { smoked/factor }\end{array}$} & \multicolumn{7}{|c|}{ Percentage } & \multirow{2}{*}{$\begin{array}{l}\text { Estimated } \\
\text { slope }\end{array}$} & \multirow{2}{*}{$\begin{array}{l}p \text { Value } \\
\text { for slope }\end{array}$} & \multirow{2}{*}{$\begin{array}{l}p \text { Value for } \\
\text { difference } \\
\text { in slopes }\end{array}$} \\
\hline & 2004 & 2005 & 2006 & 2007 & 2008 & 2009 & 2010 & & & \\
\hline \multicolumn{11}{|l|}{ Race/ethnicity: } \\
\hline \multicolumn{11}{|c|}{ Non-Hispanic Caucasian } \\
\hline Menthol & 5.3 & 5.2 & 5.5 & 5.4 & 5.5 & 4.8 & 5.3 & -0.04 & 0.44 & 0.05 \\
\hline Non-menthol & 19.7 & 19.8 & 19.0 & 19.1 & 18.6 & 18.9 & 18.1 & -0.23 & $<0.001$ & \\
\hline \multicolumn{11}{|l|}{ Non Hispanic Black } \\
\hline Menthol & 21.7 & 21.9 & 21.7 & 21.4 & 24.0 & 21.1 & 22.0 & 0.05 & 0.81 & 0.40 \\
\hline Non-menthol & 3.6 & 4.7 & 5.2 & 4.5 & 3.3 & 3.7 & 3.0 & -0.18 & 0.26 & \\
\hline \multicolumn{11}{|l|}{ Hispanic } \\
\hline Menthol & 5.3 & 6.6 & 7.0 & 6.9 & 6.0 & 7.3 & 7.7 & 0.27 & 0.07 & 0.02 \\
\hline Non-menthol & 15.2 & 15.7 & 16.6 & 13.7 & 13.3 & 14.4 & 13.6 & -0.37 & 0.10 & \\
\hline
\end{tabular}

was consistently observed across gender, household income, smoking days per month and in non-Hispanic Caucasians and Hispanics. Although an age gradient was not observed among Black smokers, young Black smokers were more likely than those in other racial/ethnic groups to smoke menthol cigarettes. Preference for menthol cigarettes by young people likely occurs because of marketing practices ${ }^{24-27}$ and product formulation. ${ }^{28}$ Analyses of tobacco industry documents confirm that young smokers may pursue mentholated brands for anticipated pleasure and may experience more pleasure and less harshness from mentholated brands than from non-mentholated varieties. ${ }^{26}$ Our data, which include the 12-15-year-old age category, control for household income and adjust for misclassification of menthol status, expand the knowledge base on this topic.

Secondly, differential progress has been observed, with the prevalence of smoking non-mentholated cigarettes declining relatively more rapidly than that of mentholated cigarettes. Increasing use of menthol relative to non-menthol cigarettes among adolescent and young adult Caucasians and young adult Hispanics is especially concerning, given the large numbers of young people in each of these racial/ethnic groups. Increased uptake of menthol cigarettes may have contributed to the slowing of the decline of adolescent smoking that has occurred since $2006 .^{29}$

Finally, there have been increases in use of several major menthol cigarette brands overall and specifically, among youth and young adults from 2004-2006 to 2008-2010. Statistically significant declines in Salem cigarette use across all age groups have been countered by dramatic increases in the use of Camel menthol, Marlboro menthol and Newport cigarettes. For example, among adolescents, Camel menthol use increased by 4.4\% points and Marlboro menthol use increased by $5.5 \%$ points during the study period. It is important to note that Marlboro and Camel made stronger gains in the adolescent and young adult markets, particularly so in Caucasians and Hispanics, than Newport. This is consistent with evidence from tobacco industry documents showing that several major tobacco companies manipulated the levels of menthol in certain cigarette brands to be closer to the low menthol levels in Newport and to target younger smokers. ${ }^{28}$ Increased use of several menthol brands among young smokers have also been influenced by the introduction of new products, including Marlboro Milds (2000), Camel No. 9 (2007), Marlboro Smooth (2007) and Camel Crush (2008). ${ }^{28} 30$ Studies have repeatedly demonstrated the impact of menthol marketing efforts that have been targeted to African-Americans and women, ${ }^{31-34}$ including the marketing of Camel No. 9 which was shown to target adolescent girls. ${ }^{35}$ Given high rates of internet and social media use among adolescents and young adults, ${ }^{36-38}$ increased use of 'Web 2.0' for tobacco marketing may also play an important role in use of particular brands among young smokers. ${ }^{39} 40$ We believe it is important for the FDA to monitor cigarette marketing for all brands targeted to all demographic subgroups via channels such as magazines, social media, the internet and direct mail, with particular attention to differentiating specific brand characteristics such as menthol. ${ }^{41}$

Kahnert and colleagues at the German Cancer Research Center have documented the recent spread, to at least 38 countries, of cigarette brands with menthol capsules in the filters. ${ }^{42}$ These new products enable users to change the flavour during the smoking process from regular to menthol. Their marketing targets young people. Tobacco companies involved include British American Tobacco, Japan Tobacco International, Philip Morris and RJ Reynolds, and in the US, these products are marketed as 'Camel Crush' and 'Marlboro NXT'. In July 2013, the European Union moved to ban menthol and flavoured cigarettes; while the FDA has already banned flavoured cigarettes, it recently called for more scientific information prior to deciding on a menthol ban.

This study is limited in several ways. First, the definition of menthol use is based on brand preference. We did not estimate the number of mentholated and non-mentholated cigarettes smoked during a period of time by each smoker. Rather, we estimate the menthol status of the brand smoked most often. Consistent with our findings, market share of menthol increased during the study period. ${ }^{43}$ Second, we measured prevalence of use and not incidence of initiation. However, prevalence in young people is largely driven by initiation rather than migration, cessation, or death. Third, we did not assess sales data prior to 2008. Nevertheless, brands such as Kool, Newport and Salem have long been classified as mentholated brands. $^{22}$ Finally, our data (table 1) indicate that the use of menthol cigarettes among older smokers was less common than among adolescent and young adult smokers. It is impossible to discern with serial cross-sectional data from 2004-2010 whether smokers switched away from menthol cigarettes as they aged. The findings might simply indicate higher rates of menthol use among more recent birth cohorts. Cohort surveys, with 

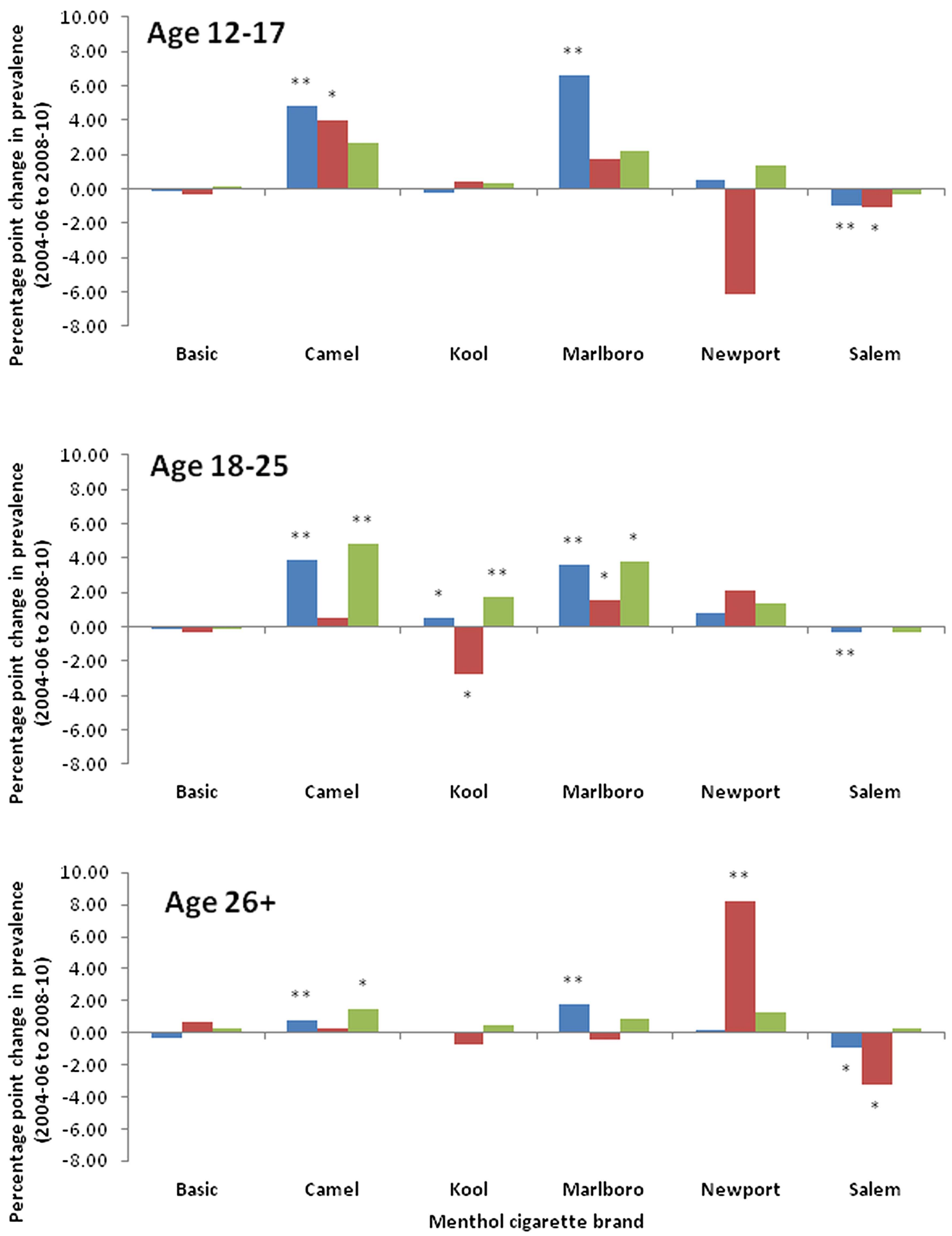

Non-Hispanic Caucasian $\square$ Non-Hispanic Black $\quad$ Hispanic

Figure 2 Percentage point change in prevalence of smoking various mentholated cigarette brands among past 30-day smokers by age and race/ ethnicity in the USA, 2004-2006 to 2008-2010. Source: National Survey on Drug Use and Health. Self-reported menthol status for Kool, Newport and Salem was adjusted if necessary using retail checkout scanner data. NB: non-Hispanic Caucasians represented by blue bars; non-Hispanic Blacks represented by red bars; Hispanics represented by green bars. ${ }^{*} p<0.05,{ }^{*} p<0.001$ for difference in prevalence between $2004-2006$ and $2008-$ 2010. Sample size $=84457 ; 43616$ for 2004-2006 and 40841 for 2008-2010.

appropriate age groups, would facilitate the study of switching behaviours.

The findings of this study complement previous research on flavoured cigarettes, ${ }^{7}$ nicotine dependence, ${ }^{5} 1213$ and menthol use among new smokers. The trend analyses reported here raise important concerns about the deleterious effects of the sale and marketing of mentholated cigarettes on progress in reducing youth smoking. Overall decreases in non-menthol cigarette use from 2004-2010 were not found for menthol use, indicating that the presence of menthol cigarettes in the marketplace is 
slowing progress in the reduction of population smoking prevalence. Concerns about menthol cigarette use in the USA have previously focused on Blacks, who primarily have smoked Newport cigarettes in most recent years. ${ }^{2}$ The data presented here also raise concerns about the increasing use of Camel menthol and Marlboro menthol cigarettes among Caucasian and Hispanic youths. Data from this study should be used to inform the FDA's decision-making processes regarding the potential public health impact of a menthol ban and to raise concern in multiple countries about the marketing of mentholated cigarettes, particularly to young people.

\section{What this paper adds}

- This study provides more precision than previous research on the use of mentholated cigarettes among young people. In the multivariable model, menthol use was found to be most likely in 12-15 year olds and 16-17 year olds. The multivariable analysis also controlled for household income, taking socioeconomic status into account.

- Previous work addressed trends in the percentage of cigarette smokers who smoked menthol cigarettes. This work presents trends in smoking menthol and non-menthol cigarettes among all persons (not just cigarette smokers) in each of the demographic categories examined, permitting the conclusion that non-menthol cigarette use is declining more rapidly than menthol cigarette use.

- Finally, the paper documents the rise of Camel Menthol and Marlboro Menthol brands among young people, particularly Caucasians and Hispanics. The information presented here should be useful to the US Food and Drug Administration and also to many other countries, where menthol cigarettes are being marketed to young people.

\footnotetext{
Author affiliations

${ }^{1}$ Department of Community Health and Health Behavior, School of Public Health and Health Professions, University at Buffalo, The State University of New York, Buffalo, New York, USA

${ }^{2}$ The Schroeder Institute for Tobacco Research and Policy Studies at Legacy, Washington, District of Columbia, USA

${ }^{3}$ Department of Health, Behavior and Society, The Johns Hopkins Bloomberg School of Public Health, Baltimore, Maryland, USA

${ }^{4}$ Biostatistics, Inc., Atlanta, Georgia, USA

${ }^{5}$ Department of Research and Evaluation, Legacy, Washington, District of Columbia, USA

${ }^{6}$ Department of Oncology, Georgetown University Medical Center, Lombardi

Comprehensive Cancer Center, Washington, District of Columbia, USA
}

Correction notice This article has been corrected since it was published Online First. In the Results section of the Abstract, the percentage at the end of the sentence 'Among cigarette smokers, menthol cigarette use was more common among $12-17$ year olds (56.7\%) and 18-25 year olds (45.0\%) than among older persons (range 30.5\% to 32.9\%).' has been corrected from "32.9\%" to "34.7\%."

Contributors GAG: conceived of the study. GAG and ACV: wrote the initial draft of the manuscript. PDM and VS: conducted the data analysis. GAG, ACV, PDM, VS, RSN, DMV and DBA: contributed to the analysis, interpretation of the data and to the review, revision and approval of the final article.

Funding This work was supported by Legacy. GAG, PDM and VS received contractual support from Legacy for their work on this project. ACV, RSN, DMV and DBA are employed at Legacy.

\section{Competing interests None.}

Provenance and peer review Not commissioned; externally peer reviewed.

\section{REFERENCES}

1 Hoffman AC. The health effects of menthol cigarettes as compared to non-menthol cigarettes. Tob Induced Dis 2011;9(Suppl 1):S7.

2 Giovino G, Sidney S, Gfroerer J, et al. Epidemiology of menthol cigarette use. Nicotine Tob Res 2004;6(Suppl 1):S67-81.

3 Mendiondo MS, Alexander LA, Crawford T. Health profile differences for menthol and non-menthol smokers: findings from the National Health Interview Survey. Addiction 2010;105(Suppl 1):124-40.

4 Ferris Wayne G, Connolly GN. Application, function, and effects of menthol in cigarettes: a survey of tobacco industry documents. Nicotine Tob Res 2004;6(Suppl 1):S43-54.

5 Hersey JC, Nonnemaker JM, Homsi G. Menthol cigarettes contribute to the appeal and addiction potential of smoking for youth. Nicotine Tob Res 2010;12(Suppl 2): S136-46

6 Ahijevych K, Garrett B. Menthol pharmacology and its potential impact on cigarette smoking behavior. Nicotine Tob Res 2004;6(Suppl 1):S17-28.

7 Klein SM, Giovino GA, Barker DC, et al. Use of flavored cigarettes among older adolescent and adult smokers: United States, 2004-2005. Nicotine Tob Res 2008; 10:1209-14.

8 Rock VJ, Davis SP, Thorne SL, et al. Menthol cigarette use among racial and ethnic groups in the United States, 2004-2008. Nicotine Tob Res 2010;12(Suppl 2): S117-24.

9 Vilsaint M-C, Green M, Xiao J, et al. Legacy first look report 13. Cigarette smoking among youth: results from the 2002 National Youth Tobacco Survey. Washington, DC: American Legacy Foundation, 2004

10 Caraballo RS, Asman K. Epidemiology of menthol cigarette use in the United States. Tob Induced Dis 2011;9(Suppl 1):S1.

11 Substance Use and Mental Health Services Administration, Center for Behavioral Health Statistics and Quality. Recent Trends in Menthol Cigarette Use. The NSDUH Report. Rockville, MD, 2011.

12 Collins C, Moolchan E. Shorter time to first cigarette of the day in menthol adolescent cigarette smokers. Addict Behav 2006;31:1460-4.

13 Wackowski O, Delnevo CD. Menthol cigarettes and indicators of tobacco dependence among adolescents. Addict Behav 2007;32:1964-9.

14 Nonnemaker J, Hersey J, Homsi G, et al. Initiation with menthol cigarettes and youth smoking uptake. Addiction 2013;108:171-8.

15 Squier CA, Mantz MJ, Wertz PW. Effect of menthol on the penetration of tobacco carcinogens and nicotine across porcine oral mucosa ex vivo. Nicotine Tob Res 2010;12:763-7.

16 H.R. 1256-111th Congress: Family Smoking Prevention and Tobacco Control Act. Secondary 2009. http://www.govtrack.us/congress/bills/111/hr1256

17 Food and Drug Administration. Candy and Fruit Flavored Cigarettes Now Illegal in United States; Step is First Under New Tobacco Law. Secondary Candy and Fruit Flavored Cigarettes Now Illegal in United States; Step is First Under New Tobacco Law 2009. http://www.fda.gov/NewsEvents/Newsroom/PressAnnouncements/ ucm183211.htm

18 Tobacco Products Scientific Advisory Committee. Menthol cigarettes and public health: review of the scientific evidence and recommendations. Rockville, MD: Center for Tobacco Products, Food and Drug Administration, 2011.

19 Giovino GA. Patterns of and recent trends in use of mentholated cigarettes in the United States. FDA Tobacco Products Scientific Advisory Committee Meeting. Silver Spring, MD, 2010

20 Substance Abuse and Mental Health Services Administration, Office of Applied Studies. National Survey on Drug Use \& Health: Methodology Reports and Questionnaires. Secondary National Survey on Drug Use \& Health: Methodology Reports and Questionnaires 2009. http://oas.samhsa.gov/nsduh/methods.cfm

21 Polednak AP. Underestimation of menthol cigarette use among young US Black smokers: comment on the article by Rock et al. Nicotine Tob Res 2012;14:248-50; author reply 51-2.

22 Nielsen AC. Sales data from the 2006 and 2009 Food/Drug/Mass cigarette data base and the 2009 C-Store data, Obtained September 2010.

23 O'Connor RJ. What brands are US smokers under 25 choosing? Tob Control 2005;14:213.

24 Cummings KM, Morley $\mathrm{CP}$, Horan JK, et al. Marketing to America's youth: evidence from corporate documents. Tob Control 2002;11(Suppl 1):15-17.

25 Henriksen L, Schleicher NC, Dauphinee AL, et al. Targeted advertising, promotion, and price for menthol cigarettes in California high school neighborhoods. Nicotine Tob Res 2012;14:116-21.

26 Klausner K. Menthol cigarettes and smoking initiation: a tobacco industry perspective. Tob Control 2011;20(Suppl 2):ii12-19.

27 Yerger VB, Przewoznik J, Malone RE. Racialized geography, corporate activity, and health disparities: tobacco industry targeting of inner cities. I Health Care Poor Underserved 2007:18(4 Suppl):10-38.

28 Kreslake JM, Wayne GF, Alpert HR, et al. Tobacco industry control of menthol in cigarettes and targeting of adolescents and young adults. Am J Public Health 2008:98:1685-92.

29 Centers for Disease Control and Prevention. Tobacco use among middle and high school students—United States, 2000-2009. MMWR Morb Mortal Wkly Rep 2010;59:1063-8. 
30 Convenience Store News. Retailers Stuck Between Tobacco Contracts. Secondary Retailers Stuck Between Tobacco Contracts Apr 7 2007. http://www.csnews.com/ top-story-business_focus-retailers_stuck_between_tobacco_contracts-42687.html

31 Anderson SJ. Marketing of menthol cigarettes and consumer perceptions: a review of tobacco industry documents. Tobacco Control 2011;20(Suppl 2):ii20-8.

32 Carpenter CM, Wayne GF, Pauly JL, et al. New cigarette brands with flavors that appeal to youth: tobacco marketing strategies. Health Aff (Millwood) 2005:24:1601-10.

33 Gardiner P. The African Americanization of menthol cigarette use in the United States. Nicotine Tob Res 2004;6(Suppl 1):S55-65.

34 Cummings KM, Giovino G, Mendicino AJ. Cigarette advertising and black-white differences in brand preference. Public Health Rep 1987;102:698-701.

35 Pierce JP, Messer K, James LE, et al. Camel No. 9 cigarette-marketing campaign targeted young teenage girls. Pediatrics 2010;125:619-26.

36 Duggan M, Brenner J. The Demographics of Social Media Users-2012. Secondary The Demographics of Social Media Users_2012 Feb 14 2013. http://www. pewinternet.org/Reports/2013/Social-media-users.aspx
37 Madden M, Lenhart A, Duggan M, et al. Teens and Technology 2013. Secondary Teens and Technology 2013 2013. http://www.pewinternet.org/Reports/2013/ Teens-and-Tech.aspx

38 Pew Internet \& American Life Project. Demographics of internet users. Secondary Demographics of internet users 2012. http://pewinternet.org/Trend-Data-\%28Adults $\% 29 /$ Whos-Online.aspx

39 Freeman B. New media and tobacco control. Tob Control 2012;21:139-44.

40 Freeman B, Chapman S. Open source marketing: Camel cigarette brand marketing in the "Web 2.0" world. Tob Control 2009;18:212-7.

41 Cruz TB. Monitoring the tobacco use epidemic IV. The vector: Tobacco industry data sources and recommendations for research and evaluation. Prev Med 2009;48(1 Suppl):S24-34.

42 German Cancer Research Center, ed. Menthol capsules in cigarette filtersIncreasing the attractiveness of a harmful product. Heidelberg, Germany: German Cancer Research Center (DKFZ), 2012.

43 Adelman DJ, Grainger M, Ayala V, et al. Menthol regulatory refresh; activity likely to increase. New York, NY: Morgan Stanley \& Co. LLC, 2012. 